\title{
BMJ Open Prevalence and risk factors of worry among teachers during the COVID-19 epidemic in Henan, China: a cross- sectional survey
}

\author{
Yanqing Wang, ${ }^{1}$ Quanman Li, ${ }^{1}$ Clifford Silver Tarimo (1) , ${ }^{1,2}$ Cuiping Wu, ${ }^{1}$ \\ Yudong Miao, ${ }^{1}$ Jian Wu (D) ${ }^{1}$
}

To cite: Wang Y, Li Q, Tarimo CS et al. Prevalence and risk factors of worry among teachers during the COVID-19 epidemic in Henan, China: a crosssectional survey. BMJ Open 2021;11:e045386. doi:10.1136/ bmjopen-2020-045386

- Prepublication history for this paper is available online. To view these files, please visit the journal online (http://dx.doi. org/10.1136/bmjopen-2020045386).

Received 29 September 2020 Accepted 09 June 2021

Check for updates

(c) Author(s) (or their employer(s)) 2021. Re-use permitted under CC BY-NC. No commercial re-use. See rights and permissions. Published by BMJ.

${ }^{1}$ College of Public Health, Zhengzhou University, Zhengzhou, Henan, China ${ }^{2}$ Department of Science and Laboratory Technology, Dar es Salaam Institute of Technology, Dar es Salaam, Tanzania

Correspondence to Professor Yudong Miao; meldon@zzu.edu.cn and Professor Jian Wu; jianwuzzu@163.com

\section{ABSTRACT}

Objective To evaluate the level of worry and its influencing factors during the COVID-19 epidemic among teachers in Henan Province in China.

Study design A cross-sectional study was conducted. Methods We designed a cross-sectional survey that included 88611 teachers from three cities in Henan Province, China between 4 February 2020 and 12 February 2020. Level of worry was measured using a five-item Likert scale, with 1 being 'not worried' and 5 being 'very worried'. The $\mathrm{OR}$ and $95 \% \mathrm{Cl}$ of potential influencing factors for level of worry among study participants were estimated using ordinal logistic regression models. Results About $59 \%$ of teachers reported being 'very worried' about the COVID-19 epidemic. The proportion of female teachers was higher than of male teachers (60.33\% vs $52.89 \%)$. In all age groups considered in this study, a 'very worried' condition accounted for the highest proportion. The age group 40-49 years had the lowest proportion of participants who were very worried, $52.34 \%$ of whom were men and $58.62 \%$ were women. After controlling for potential confounding factors, age, education level, type of teacher, school location, attention level, fear level, anxiety level and behaviour status were all related to level of worry (all $p<0.05$ ).

Conclusion During the COVID-19 epidemic, there was a high proportion of teachers who were 'very worried' about the situation in Henan Province, China. Our study may remind policymakers to consider factors including age, educational status, type of teacher, school location, source of information on COVID-19, attention level, anxiety level, fear level and behaviour status to alleviate worry.

\section{INTRODUCTION}

Since the first cluster of cases was identified in China in December 2019, COVID-19 has continued to pose public health attention around the country. ${ }^{1-3}$ With its highly contagious characteristics, containment of COVID-19 requires joint and comprehensive measures, including city lockdowns, proper hygiene practices and social distancing. Since then, the Chinese government has been imposing strict health policies and strategies
Strengths and limitations of this study

- The study has a large sample size.

- The study was able to recruit a representative population of highly educated urban and rural teachers to ensure data quality to some degree.

- Ordinal logistic regression model was used to conduct a more effective statistical analysis of data.

- Due to the cross-sectional nature of the study, we were unable to determine trends in the level of 'worry' among teachers at different stages of the COVID-19 epidemic and to make any inferences about causality.

to mitigate the propagation of new infections. ${ }^{4}$ However, it did not only incur substantial losses to the global economy and trade, but also posed great challenges to medical and health services supply. ${ }^{5}$ Epidemics may induce panic to the general public. ${ }^{6}$ In these times of uncertainty, people are worried not only about the epidemic, but also about income, employment and other factors that have direct effects on survival and life due to changes in the working environment during lockdowns.

Worry is a form of repetitive thinking that involves negative thoughts about future events and is regarded as a major source of anxiety. ${ }^{7}$ A study investigating the sociocultural features of the influenza pandemic showed that worry towards influenza was the most commonly reported symptom across various sociocultural populations. ${ }^{8}$ We think that the level of worry plays an important role in public health, especially when coupled with the epidemic situation of a fastspreading infectious disease. Strengthening public awareness of the relationship between worry status and the ongoing epidemic may aid in the development of effective management and preventive measures. ${ }^{9}$ Baiano et 
$a l^{10}$ proposed that mindfulness-based interventions that improve the ability to focus on the present moment could be a valuable approach to supporting individuals who experience worry and fear related to the COVID-19 outbreak. Based on a cross-sectional survey of 2007 participants, Ho et $a l^{11}$ discovered that information explored from the academia may help facilitate public education and reduce public worry in cases of infectious disease outbreaks. In addition, Wahlund $e t a l^{12}$ introduced a brief digital and easily scalable self-guided psychological intervention that can significantly reduce dysfunctional worry and the associated behavioural symptoms related to the COVID-19 pandemic.

Henan Province, which borders Hubei Province, has a population of more than 100 million, with a high level of resident mobility. As of 17 June 2020, Henan Province has a total of 1273 confirmed cases, with a cumulative incidence rate of 1.32 per 100000 , which was higher than in other provinces and cities outside Hubei and closely related to the geographical location of Henan Province. ${ }^{13} 14$ The COVID-19 epidemic has had a negative impact on the global educational system, particularly when school closure policies were implemented. ${ }^{15}$ As soon as the epidemic broke out, all cities in Henan Province took emergency measures such as closing of schools. ${ }^{14}$ In this scenario, teachers' health may be of concern due to the reported high incidence of occupational stress following the closure of schools in response to the epidemic. ${ }^{16}$ There has not been a lot of research on teachers' worry status; however, many previous studies have focused on teachers' anxiety and its effects during COVID-19. According to $\mathrm{Li}$ et al, ${ }^{17}$ improper wearing of mask is an important factor that contributes to an increase in anxiety during the epidemic. A recent study from Arab countries indicates that the epidemic has caused anxiety among teachers, restricting their ability to teach properly. ${ }^{18}$ Moreover, it has been shown that indoor physical activity prevents anxiety and depression during lockdowns. ${ }^{19}$ Worry, rather than anxiety, appears to be more prevalent in previous studies. ${ }^{20}$ Teachers at all levels of education may be 'worried'about the ongoing COVID-19 epidemic. As a result, we believe that a timely understanding of worry status in this population is critical.

The current study aimed to assess teachers' level of worry and identify its potential risk factors in Henan, China during the COVID-19 epidemic. Moreover, since gender differences have been reported as among the predisposing factors of worry, anxiety and emotional distress, with women being more worried, ${ }^{21}$ anxious ${ }^{22}$ and at higher risk of emotional distress compared with men ${ }^{23}$ here we also looked at possible sex differences in the psychological response to quarantines. ${ }^{10}$ Findings of this study may aid in informing and alerting government agencies and healthcare professionals on the general mental health status among populations and help plan ahead proper strategies to face future epidemics.

\section{METHODS}

\section{Study design}

We designed a cross-sectional survey using an online platform ('SurveyStar', Changsha RanXing Science and Technology, Shanghai, China) and developed an anonymous online questionnaire to assess demographic characteristics, knowledge, attention, behaviour, mental state and other factors related to COVID-19 among the participants.

\section{Setting}

To estimate level of worry during the COVID-19 epidemic, we implemented this study using a questionnaire link which was sent to the respondents through social media ('WeChat', Tencent, Shenzhen, China). We recruited teachers, including primary, junior, high school and university teachers, aged $\geq 18$ years residing in Zhengzhou, Xinyang and Xinxiang City of Henan Province, China during 4 February 2020 and 12 February 2020.

\section{Participants and sample size}

Sample size was calculated using the formula $\mathrm{N}=\mathrm{z}^{2} * \mathrm{p}(1-\mathrm{p}) /$ $\mathrm{d}^{2}$ in the epidemiological cross-sectional survey, where $\mathrm{p}=0.59, \mathrm{z}=1.96$ and $\mathrm{d}=0.05$. A minimum sample of 372 teachers was required for this study. We eventually enrolled 88611 teachers (including 243 retired teachers; the retirement age of teachers in China is over 60 years) from a total population of 93518 after excluding participants who spent less than $100 \mathrm{~s}$ answering the questions completely and those younger than 18 years $(n=4907)$.

Intraclass correlation coefficient for the test-retest reliability of the self-made questionnaire used was $0.81 .{ }^{24}$ The weighted kappa that was conducted to assess agreement between test and retest showed a substantial agreement of 0.73 between the two occasions of answering the selfmade questions. ${ }^{25}$

All participants consented for participation in this study.

\section{Patient and public involvement}

Patients and/or the public were not involved in the design, or conduct, or reporting or dissemination plans of this research.

\section{Data sources}

Participants were asked to provide information about their age, sex, marital status, education level, knowledge about COVID-19, behaviour status, attention level, mental state including worry, fear and anxiety, and other factors including teachers' category and school location. Sources of information on COVID-19 were classified as independent learning (including tools such as WeChat/Weibo and television/radio), structured learning (including tools such as documents issued by the government or schools) and mixed learning (including independent and structured learning). Teachers' levels of attention, fear and anxiety towards the epidemic were classified into high, moderate and low. Parameters used to examine participants' behaviour included 'wearing a mask', 'frequency 
of hand washing', 'frequency of going outdoor' and 'spring festival travel plans'. Participants' behaviour was classified as 'high' if they correctly answered all of the questions in this session and as 'moderate' if they only got a portion of the answers correct. If participants got all incorrect answers in this session, their behaviour status was considered 'low'.

The Generalized Anxiety Disorder (GAD-7) tool was used to assess anxiety. The tool has a sensitivity of $89 \%$ and a specificity of $82 \%$. A score of 10 or higher was thought to be a reasonable cut point for identifying cases. Cut points of 5, 10 and 15 on GAD-7 may be interpreted as mild, moderate and severe level of anxiety, respectively. ${ }^{26}$

The level of worry of teachers during the COVID-19 epidemic in China was assessed by the question 'How worried are you on the novel coronavirus infection?' and their responses were scored on a 5 -item Likert scale: $1=$ not worried, $2=$ not too worried, $3=$ generally worried, $4=$ more worried and $5=$ very worried.

\section{Statistical methods}

Pearson $\chi^{2}$ test was used to test for differences among categorical variables, while analysis of variance was applied for continuous variables. We developed ordinal logistic regression models for risk factors. The adjusted model was controlled by age, educational status, type of teacher, school location, marital status, information source, attention level, anxiety level, fear level and behaviour status.

All analyses were performed using SAS V.9.4 and STATA V.14. All statistical tests were two-sided, with $\mathrm{p}<0.05$ considered statistically significant.

\section{RESULTS}

\section{Characteristics of the participants}

Among the 88611 teachers, more than half $(58.61 \%)$ expressed a 'very worried' condition during the outbreak of COVID-19 in China, $10881(52.89 \%)$ of whom were male teachers and $41126(60.33 \%)$ were female teachers. The mean age of the participants was $36(\mathrm{SD}=9)$ years, ranging from 18 to 79 years. The overall mean score for level of worry among the study participants was 4.47 $(\mathrm{SD}=0.74)$. We found different levels of worry by age, educational status, type of teacher, school location, marital status, attention level, information source, anxiety level, fear level and behaviour status (all $\mathrm{p}<0.0001$ ). Details of the characteristics of the participants stratified by level of worry are shown in table 1.

\section{Level of worry by age group}

During the COVID-19 epidemic in China, teachers generally had a high level of worry, with $91.16 \%$ being either 'very worried' or 'more worried'. Figure 1 shows the different proportions of level of worry between male and female teachers by age and categories of worry. Gender and age group were found to be consistent in all levels of worry, showing that a 'very worried' status accounted for the highest proportion in all age groups, with $52.77 \%$,
$53.22 \%, 52.34 \%$ and $53.31 \%$ in the $18-29$ years, $30-39$ years, $40-49$ years and $\geq 50$ years among male age groups, respectively, and $60.70 \%, 61.04 \%, 58.62 \%$ and $59.54 \%$ in the $18-29$ years, $30-39$ years, $40-49$ years and $\geq 50$ years among female age groups, respectively. Furthermore, about $33 \%$ of male and $32 \%$ of female teachers were 'more worried'. We found a small proportion of teachers who were not worried ( $1.36 \%$ male vs $0.44 \%$ female) about the ongoing epidemic across all age groups. Teachers in the age group 40-49 years were shown to have the lowest proportion of 'very worried' condition, of whom $52.34 \%$ (SE $0.60 \%$ ) were male and $58.62 \%$ (SE $0.41 \%$ ) were female.

\section{Risk factors of level of worry among male teachers}

Adjusted analyses show that male teachers aged between 18 and 29 were more likely to have a higher level of worry compared with all other age groups. This study also found that teachers with college education were more likely to report having a higher level of worry compared with those of other educational status, such as bachelor's and master's degree. However, participants in the 'others' category (ie, no college, bachelor's or master's education) had higher odds of suffering from a higher level of worry (OR 1.33, 95\% CI 1.11 to 1.59 ). Compared with primary school teachers, junior high school (OR 0.82, 95\% CI 0.76 to 0.88 ) and senior high school (OR $0.85,95 \%$ CI 0.79 to 0.92 ) teachers were less likely to suffer from a higher level of worry. Similarly, teachers from county-level urban and rural schools had $21 \%$ (OR $0.79,95 \%$ CI 0.74 to 0.85 ) and $16 \%$ (OR $0.84,95 \%$ CI 0.77 to 0.90 ) less odds of having a higher level of worry compared with those residing in urban areas. Teachers with a moderate level of attention towards the epidemic were $70 \%$ (OR $0.30,95 \%$ CI 0.21 to $0.43)$ less likely to have a higher level of worry. Teachers with moderate level of fear (OR $0.05,95 \%$ CI 0.05 to 0.07 ) and low level/no fear (OR $0.01,95 \%$ CI 0.01 to 0.02 ) had a strong protective effect of keeping a lower level of worry than those with a high level of fear. Similarly, teachers with low level/no anxiety were also less likely (OR 0.46, $95 \%$ CI 0.37 to 0.58 ) to be very worried compared with those with a high level of anxiety. Teachers who did not execute proper behaviours were less likely (OR 0.92, 95\% CI 0.85 to 0.99 ) to suffer from a higher level of worry about the epidemic situation compared with those who showed proper healthy behaviours. Detailed information is shown in table 2.

\section{Risk factors of level of worry among female teachers}

Adjusted analyses show that female teachers aged between 30 and 39 years (OR $0.92,95 \%$ CI 0.88 to 0.97 ) and between 40 and 49 years (OR $0.90,95 \%$ CI 0.85 to 0.95 ) had lower odds and were less likely to suffer from a higher level of worry compared with the lowest age group (18-29 years). This study also found that teachers with college education were more likely to report having a higher level of worry compared with those of other educational status, such as bachelor's and master's degree. However, 
Table 1 Characteristics of study participants by level of worry

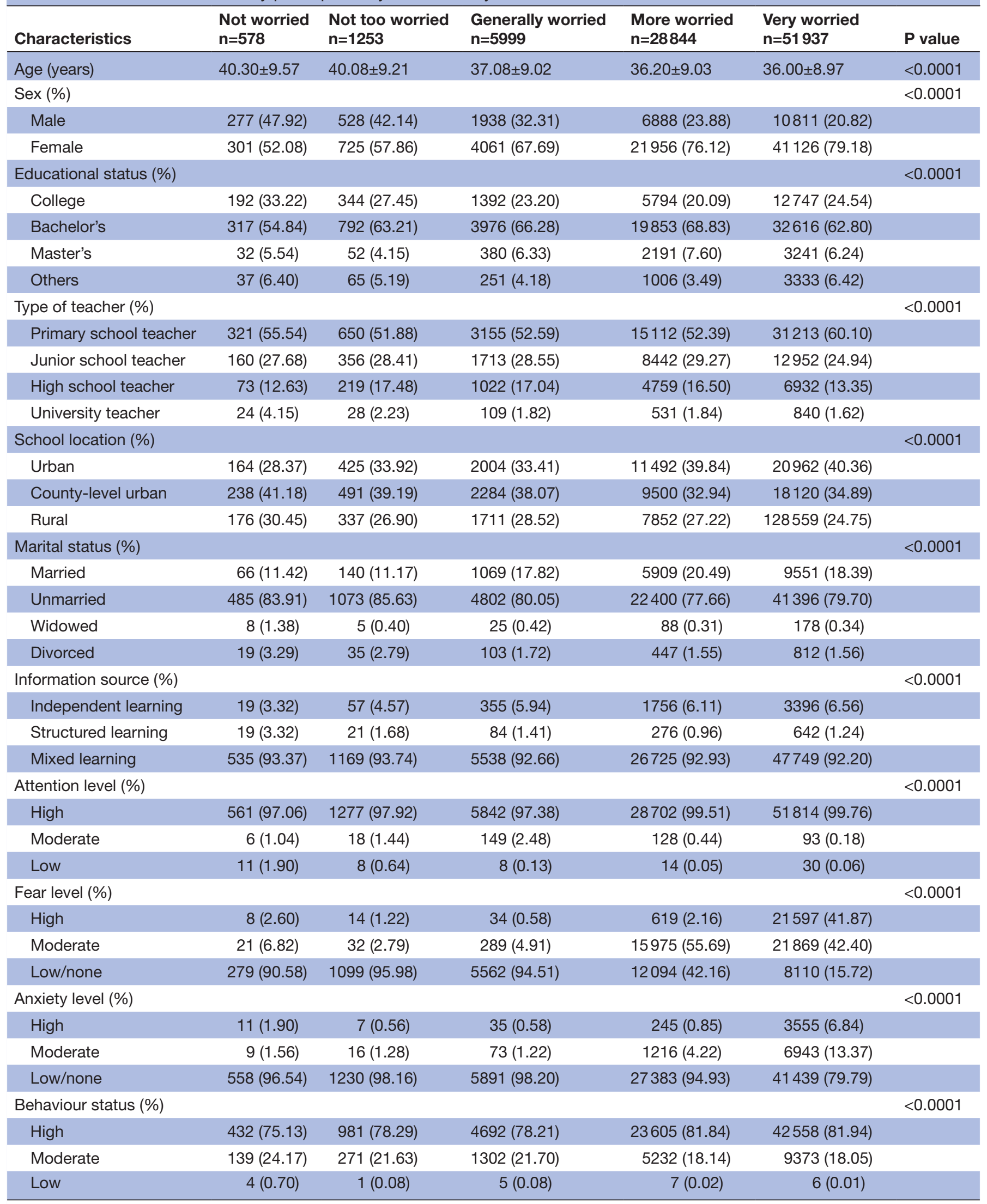

Data are mean (SD) or number (percentage).

$\mathrm{P}$ value is from analysis of variance test or $\chi^{2}$ test for continuous variables and categorical variables. 

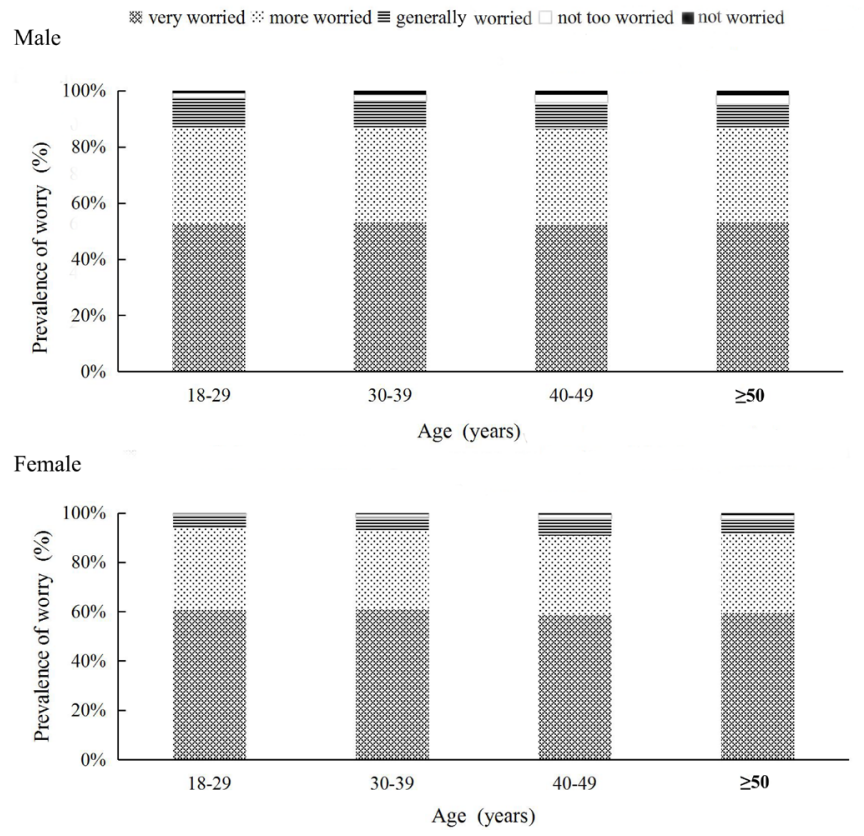

Figure 1 Proportion of level of worry among teachers stratified by sex during the COVID-19 epidemic in China based on age groups.

participants in the 'others' category (ie, no college, bachelor's or master's education) had higher odds of suffering from a higher level of worry (OR 1.11, 95\% CI 1.02 to 1.22). Compared with primary school teachers, junior school (OR $0.85,95 \%$ CI 0.81 to 0.88 ) and high school (OR $0.84,95 \%$ CI 0.80 to 0.89 ) teachers had lower odds and were less likely to suffer from a higher level of worry. Similarly, teachers from county-level urban and rural schools had 9\% (OR 0.91, 95\% CI 0.87 to 0.95 ) and $14 \%$ (OR $0.86,95 \%$ CI 0.83 to 0.90 ) less odds of suffering from a higher level of worry compared with those residing in urban areas. Teachers with a moderate level of attention (OR $0.20,95 \%$ CI 0.16 to 0.25 ) and low level/no attention (OR $0.41,95 \%$ CI 0.21 to 0.78 ) had about $80 \%$ and $60 \%$ less odds of suffering from a higher level of worry. Teachers with moderate level of anxiety (OR $0.64,95 \%$ CI 0.53 to 0.76 ) and low level/no anxiety (OR $0.31,95 \%$ CI 0.26 to 0.36 ) were also less likely to encounter a very worried condition compared with those with a high level of anxiety. Similarly, teachers with moderate level of fear (OR $0.05,95 \%$ CI 0.05 to 0.06 ) and low level/no fear (OR $0.01,95 \%$ CI 0.01 to 0.01 ) had a strong protective effect of keeping a lower level of worry than those with a high level of fear. Teachers who did not execute proper behaviours were less likely (OR $0.94,95 \%$ CI 0.90 to 0.99 ) to be very worried about the epidemic situation compared with those who showed proper healthy behaviours. Detailed information is shown in table 3 .

\section{DISCUSSION}

This study aimed to investigate the level of worry among teachers by gender during the COVID-19 epidemic and its influencing factors in Henan, China, and hence provide reference for policymakers. In the context of the epidemic, we found that the level of worry among teachers was not encouraging, with only $0.65 \%$ of teachers reporting being not worried and $58.61 \%$ and $32.55 \%$ of teachers reporting being very worried and more worried about the epidemic, respectively, suggesting that the epidemic had imposed a significant amount of worry. Furthermore, age, educational status, type of teacher, school location, attention level, anxiety level, fear level and behaviour status were associated with worry.

The ongoing COVID-19 epidemic made everyone worried about becoming infected. This worried condition is also fuelled by fear of lack of sufficient medical resources and financial crisis. ${ }^{11} 1727-29$ Our findings are consistent with previous research showing that male participants reported less worry than female participants. ${ }^{30}$ Caroppo $e t a \rho^{31}$ found gender differences in the response to lockdowns in a study published not long ago on the unequal effects of the national lockdown on mental and social health in Italy. In this study, female teachers are more likely to be worried, which may be related to their sensitivity to psychological stress and the higher perceived susceptibility, resulting in increased disease-related worries. ${ }^{32} 33$ The older age is associated with lower level of worry, which is similar to previous studies showing that older adults exhibit less worry and fewer post-traumatic stress disorder symptoms following natural disasters and terrorist attacks. ${ }^{34}{ }^{35}$ This may be due to older adults possessing superior emotion regulation and coping strategies. ${ }^{36}$

We also found that educational status and type of teacher correlated with level of worry, which was similar to the results of a study showing that teachers of higher educational status experience less psychological problems than those of lower educational status. ${ }^{37}$ University teachers also represent teachers of higher educational status to a large extent in China. School location was also a factor affecting teachers' levels of worry, which may be related to the regional differences in the number of confirmed COVID-19 cases, where there were more cases in urban than in rural areas. ${ }^{38}$ In the survey area of this study, patients are immediately isolated in a special city hospital for isolation and treatment if confirmed positive. Urban school teachers seemed to be affected when there are cases in their area, and to some extent would worry and hesitate to seek medical attention. ${ }^{3940}$

According to reports of the National Mental Health Development in China (2017-2018), the mental health of teachers is declining annually. Studies show that the mental health condition of Chinese teachers has become much worse than normal. ${ }^{41-43}$ The COVID-19 epidemic has caused unprecedented damage to the educational system worldwide. In particular, teachers are intellectual resources and have to face various types of financial, physical and mental struggles due to COVID-19. ${ }^{274}$ Previous experience suggests that the public is likely to experience anxiety, depression and panic attacks when faced with highly contagious diseases. ${ }^{45}$ In our study, both male and 
Table 2 Independent association between characteristics and level of worry among male teachers during the COVID-19 epidemic in China

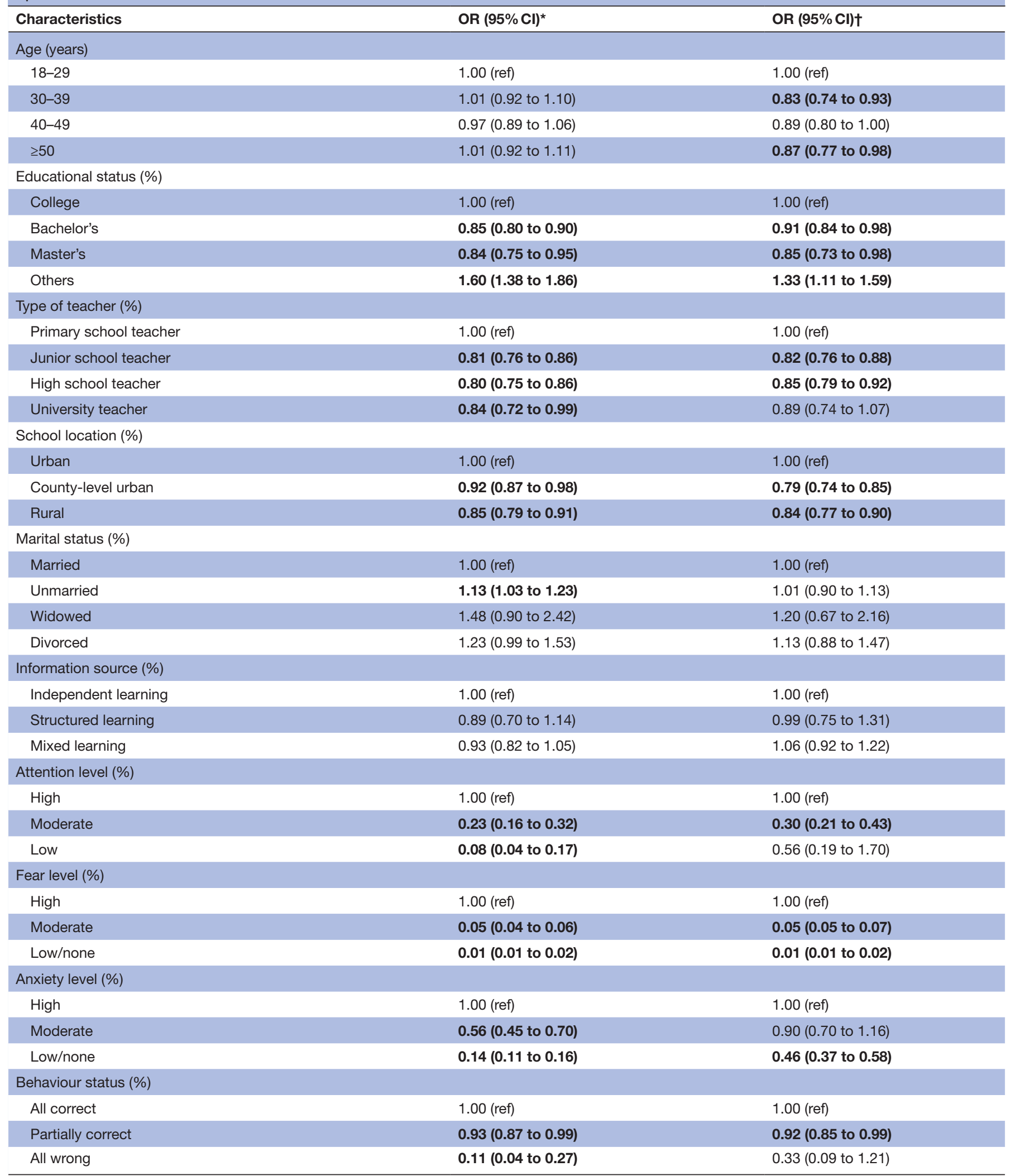

The bold type: $\mathrm{P}<0.05$.

*Unadjusted.

†Adjusted for age, educational status, type of teacher, school location, married status, information source, attention level, fear level, anxiety level and behaviour status.

ref, reference. 
Table 3 Independent association between characteristics and level of worry among female teachers during the COVID-19 epidemic in China

\begin{tabular}{|c|c|c|}
\hline Characteristics & OR $(95 \% \mathrm{Cl})^{*}$ & OR $(95 \% \mathrm{Cl}) \dagger$ \\
\hline \multicolumn{3}{|l|}{ Age (years) } \\
\hline $18-29$ & 1.00 (ref) & 1.00 (ref) \\
\hline $30-39$ & 0.99 (0.96 to 1.03$)$ & 0.92 (0.88 to 0.97$)$ \\
\hline $40-49$ & 0.88 (0.85 to 0.92$)$ & 0.90 (0.85 to 0.95$)$ \\
\hline$\geq 50$ & 0.92 (0.86 to 0.98$)$ & 0.97 (0.89 to 1.05 ) \\
\hline \multicolumn{3}{|l|}{ Educational status (\%) } \\
\hline College & 1.00 (ref) & 1.00 (ref) \\
\hline Bachelor's & 0.81 (0.78 to 0.84$)$ & 0.84 (0.80 to 0.88$)$ \\
\hline Master's & $0.75(0.71$ to 0.80$)$ & 0.81 (0.74 to 0.88 ) \\
\hline Others & 1.40 (1.30 to 1.52$)$ & 1.11 (1.02 to 1.22$)$ \\
\hline \multicolumn{3}{|l|}{ Type of teacher (\%) } \\
\hline Primary school teacher & 1.00 (ref) & 1.00 (ref) \\
\hline Junior school teacher & 0.80 (0.77 to 0.82$)$ & 0.85 (0.81 to 0.88 ) \\
\hline High school teacher & $0.76(0.72$ to 0.80$)$ & 0.84 (0.80 to 0.89$)$ \\
\hline University teacher & 0.78 (0.69 to 0.89$)$ & 0.90 (0.77 to 1.04$)$ \\
\hline \multicolumn{3}{|l|}{ School location (\%) } \\
\hline Urban & 1.00 (ref) & 1.00 (ref) \\
\hline County-level urban & 0.97 (0.94 to 1.01$)$ & 0.91 (0.87 to 0.95 ) \\
\hline Rural & 0.85 (0.81 to 0.88$)$ & 0.86 (0.83 to 0.90$)$ \\
\hline \multicolumn{3}{|l|}{ Married status (\%) } \\
\hline Married & 1.00 (ref) & 1.00 (ref) \\
\hline Unmarried & 1.10 (1.06 to 1.14$)$ & 1.00 (0.95 to 1.05$)$ \\
\hline Widowed & 0.89 (0.69 to 1.15$)$ & 0.86 (0.64 to 1.15$)$ \\
\hline Divorced & 0.93 (0.82 to 1.05$)$ & 0.98 (0.85 to 1.13$)$ \\
\hline \multicolumn{3}{|l|}{ Information source (\%) } \\
\hline Independent learning & 1.00 (ref) & 1.00 (ref) \\
\hline Structured learning & 1.07 (0.90 to 1.25$)$ & 1.08 (0.89 to 1.30$)$ \\
\hline Mixed learning & 0.91 (0.86 to 0.97$)$ & 1.07 (1.00 to 1.15$)$ \\
\hline \multicolumn{3}{|l|}{ Attention level (\%) } \\
\hline High & 1.00 (ref) & 1.00 (ref) \\
\hline Moderate & $0.14(0.12$ to 0.18$)$ & 0.20 (0.16 to 0.25$)$ \\
\hline Low & 0.27 (0.15 to 0.47$)$ & 0.41 (0.21 to 0.78$)$ \\
\hline \multicolumn{3}{|l|}{ Fear level (\%) } \\
\hline High & 1.00 (ref) & 1.00 (ref) \\
\hline Moderate & 0.05 (0.04 to 0.05$)$ & 0.05 (0.05 to 0.06$)$ \\
\hline Low/none & 0.01 (0.01 to 0.01$)$ & 0.01 (0.01 to 0.01$)$ \\
\hline \multicolumn{3}{|l|}{ Anxiety level (\%) } \\
\hline High & 1.00 (ref) & 1.00 (ref) \\
\hline Moderate & $0.39(0.33$ to 0.46$)$ & 0.64 (0.53 to 0.76$)$ \\
\hline Low/none & 0.08 (0.07 to 0.10$)$ & 0.31 (0.26 to 0.36$)$ \\
\hline \multicolumn{3}{|l|}{ Behaviour status (\%) } \\
\hline All correct & 1.00 (ref) & 1.00 (ref) \\
\hline Partially correct & $0.93(0.90$ to 0.97$)$ & 0.94 (0.90 to 0.99$)$ \\
\hline All wrong & 0.10 (0.04 to 0.24$)$ & 0.32 (0.10 to 1.05$)$ \\
\hline
\end{tabular}

*Unadjusted.

†Adjusted for age, educational status, type of teacher, school location, married status, information source, attention level, fear level, anxiety level and behaviour status. 
female teachers experienced a relatively complex mental state, and there was a positive correlation between their level of worry and attention level, fear level and anxiety status towards the epidemic. In particular, the level of fear among teachers had a strong influence on the level of worry. Fear may be a central construct in explaining these negative individual and societal consequences of the coronavirus epidemic. ${ }^{20}$

We also found that teachers whose behavior status was deemed inappropriate had relatively lower worry levels compared with ones that exhibited appropriate behavior. In other words, appropriate behaviors (such as: mask wearing, frequency of hand washing, frequency of going outdoor for dinner, and spring festival travel) may be a consequence of teachers' 'very worried' condition in our study, which confirmed the findings of earlier research indicating that certain risk perceptions would promote proper conduct or behaviour. ${ }^{45}{ }^{46}$ In addition, this study may also confirm that teachers were more worried about the epidemic due to the more information they perceived. ${ }^{47}$ Further investigation into the relationship between information perception and risk of worry is required. However, the government and policymakers should pay attention to people's psychological well-being and raise awareness on the 'worry situation' with regard to the ongoing epidemic, which may aid in the development of effective management and preventive strategies. ${ }^{9}$

Our study had some limitations that must be taken into account when interpreting the results. First, this was an online and self-reported study conducted in the middle of an outbreak, a situation which might have introduced some amount of reporting bias. During this time, China had already implemented lockdown strategies as well as other strict policies such that we could not organise professionals to conduct mental state diagnostics for the study participants. Second, the study could only reflect the level of worry during the critical period of the outbreak and cannot reflect the level of worry at different stages of the epidemic. More studies are needed with longer-term monitoring of participants. In addition, we were unable to make inferences on causality due to the cross-sectional nature of the study. Therefore, more research with cohort study design is required to infer relationships and confirm the stability of our findings. Finally, our findings might be limited to teachers in Henan Province and may not be generalisable to the entire Chinese teaching population.

\section{CONCLUSIONS}

During the COVID-19 epidemic, the proportion of teachers who were very worried was particularly high in Henan Province, especially among female teachers. Factors including age, educational status, type of teacher, school location, information source, attention level, anxiety level, fear level and behaviour status can alert policymakers in Henan that the relative implications of these factors can be considered in order to alleviate worry.

\section{Twitter Clifford Silver Tarimo @clifford_silver}

Acknowledgements We thank Zhuowen He, Yu Feng, Qingqing Zhang, Zhanlei Shen, Dongyang Xu, Zihan Mu, Xiaonan Du and Zunzun Nie for their efforts in collecting the information. We also thank the participating teachers in Henan Province, China.

Contributors YW and QL designed research. YW collected the data. YW and QL analysed the data and drafted the manuscript. YM, CST, CW and JW revised the manuscript. YM and JW had primary responsibility for the final content. All authors read and approved the final manuscript.

Funding This study was funded by the Zhengzhou University 2020 Special Project of Discipline Construction (grant no. XKZDQY202007); 2021 Postgraduate Education Reform and Quality Improvement Project of Henan Province (grant no. YJS2021KC07); and National Key R\&D Program of China (grant no 2018YFC0114501); and Zhengzhou University 2021 Cultivation Fund (grant no. JC21738031).

\section{Competing interests None declared.}

Patient and public involvement Patients and/or the public were not involved in the design, or conduct, or reporting, or dissemination plans of this research.

Patient consent for publication Not required.

Ethics approval This study was approved by the Zhengzhou University Life Science Ethics Review Committee.

Provenance and peer review Not commissioned; externally peer reviewed. Data availability statement Data are available upon reasonable request.

Open access This is an open access article distributed in accordance with the Creative Commons Attribution Non Commercial (CC BY-NC 4.0) license, which permits others to distribute, remix, adapt, build upon this work non-commercially, and license their derivative works on different terms, provided the original work is properly cited, appropriate credit is given, any changes made indicated, and the use is non-commercial. See: http://creativecommons.org/licenses/by-nc/4.0/.

\section{ORCID iDs}

Clifford Silver Tarimo http://orcid.org/0000-0002-0672-9471

Jian Wu http://orcid.org/0000-0001-5840-4233

\section{REFERENCES}

1 Hoehl S, Rabenau H, Berger A, et al. Evidence of SARS-CoV-2 infection in returning travelers from Wuhan, China. N Engl J Med Overseas Ed 2020;382:1278-80.

2 Zhu N, Zhang D, Wang W, et al. A novel coronavirus from patients with pneumonia in China, 2019. N Engl J Med 2020;382:727-33.

3 Mizumoto K, Kagaya K, Chowell G. Early epidemiological assessment of the transmission potential and virulence of coronavirus disease 2019 (COVID-19) in Wuhan City, China, JanuaryFebruary, 2020. BMC Med 2020;18:217.

$4 \mathrm{Wu}$ J, Bhuyan SS, Fu X. Enhancing global health engagement in 21st century China. BMJ Glob Health 2020;5:e002194.

5 Phelan AL, Katz R, Gostin LO. The novel coronavirus originating in Wuhan, China: challenges for global health governance. JAMA 2020;323:709-10.

6 Medley GF, Vassall A. When an emerging disease becomes endemic. Science 2017;357:156-8.

7 Borkovec TD, Robinson E, Pruzinsky T, et al. Preliminary exploration of worry: some characteristics and processes. Behav Res Ther 1983;21:9-16.

8 Sundaram N, Schaetti C, Purohit V, et al. Cultural epidemiology of pandemic influenza in urban and rural Pune, India: a cross-sectional, mixed-methods study. BMJ Open 2014;4:e006350.

9 Ro J-S, Lee J-S, Kang S-C, et al. Worry experienced during the 2015 middle East respiratory syndrome (MERS) pandemic in Korea. PLoS One 2017;12:e0173234.

10 Baiano C, Zappullo I, Conson M. Tendency to Worry and Fear of Mental Health during Italy's COVID-19 Lockdown. Int J Environ Res Public Health 2020;17:5928.

11 Ho H-Y, Chen Y-L, Yen C-F. Different impacts of COVID-19-related information sources on public worry: an online survey through social media. Internet Interv 2020;22:100350.

12 Wahlund T, Mataix-Cols D, Olofsdotter Lauri K, et al. Brief online cognitive behavioural intervention for dysfunctional worry related to the COVID-19 pandemic: a randomised controlled trial. Psychother Psychosom 2021;90:191-9. 
13 Ma Q, Li C, Zhai Y, et al. Epidemic features of coronavirus disease 2019 in Henan Province. Zhong Nan Da Xue Xue Bao Yi Xue Ban 2020;45:582-90.

14 Yang X, Chen X, Ding C, et al. Epidemiological investigation and prevention control analysis of the longitudinal distribution of COVID-19 in Henan Province, China. mSphere 2020;5:e00867-20.

15 Hoang A-D, Ta N-T, Nguyen Y-C, et al. Dataset of ex-pat teachers in Southeast Asia's intention to leave due to the COVID-19 pandemic. Data Brief 2020;31:105913.

16 Mérida-López S, Extremera N, Rey L. Emotion-regulation ability, role stress and teachers' mental health. Occup Med 2017;67:540-5.

$17 \mathrm{Li} \mathrm{Q}$, Tarimo CS, Miao Y, et al. Effects of mask wearing on anxiety of teachers affected by COVID-19: a large cross-sectional study in China. J Affect Disord 2021;281:574-80.

18 Al Lily AE, Ismail AF, Abunasser FM, et al. Distance education as a response to pandemics: coronavirus and Arab culture. Technol Soc 2020;63:101317.

19 Aperribai L, Cortabarria L, Aguirre T, et al. Teacher's physical activity and mental health during Lockdown due to the COVID-2019 pandemic. Front Psychol 2020;11:577886.

20 Mertens G, Gerritsen L, Duijndam S, et al. Fear of the coronavirus (COVID-19): predictors in an online study conducted in March 2020. $J$ Anxiety Disord 2020;74:102258.

21 Stavosky JM, Borkovec TD. The phenomenon of worry. Women Ther 1987;6:77-95.

22 McLean CP, Anderson ER. Brave men and timid women? A review of the gender differences in fear and anxiety. Clin Psychol Rev 2009;29:496-505.

23 Lai J, Ma S, Wang Y, et al. Factors associated with mental health outcomes among health care workers exposed to coronavirus disease 2019. JAMA Netw Open 2020;3:e203976.

24 Cicchetti DV. Guidelines, criteria, and rules of thumb for evaluating normed and standardized assessment instruments in psychology. Psychol Assess 1994;6:284-90.

25 Landis JR, Koch GG. The measurement of observer agreement for categorical data. Biometrics 1977;33:159-74.

26 Spitzer RL, Kroenke K, Williams JBW, et al. A brief measure for assessing generalized anxiety disorder: the GAD-7. Arch Intern Med 2006;166:1092-7.

27 Li Q, Miao Y, Zeng X, et al. Prevalence and factors for anxiety during the coronavirus disease 2019 (COVID-19) epidemic among the teachers in China. J Affect Disord 2020;277:153-8.

28 Nelson LM, Simard JF, Oluyomi A, et al. Us public concerns about the COVID-19 pandemic from results of a survey given via social media. JAMA Intern Med 2020;180:1020-2.

29 Sobkow A, Zaleskiewicz T, Petrova D, et al. Worry, risk perception, and Controllability predict intentions toward COVID-19 preventive behaviors. Front Psychol 2020;11:582720.

30 Crittendon J, Hopko DR. Assessing worry in older and younger adults: psychometric properties of an abbreviated Penn state worry questionnaire (PSWQ-A). J Anxiety Disord 2006;20:1036-54.
31 Caroppo E, De Lellis P, Lega I, et al. Unequal effects of the National lockdown on mental and social health in Italy. Ann Ist Super Sanita 2020;56:497-501.

32 Akan H, Gurol Y, Izbirak G, et al. Knowledge and attitudes of university students toward pandemic influenza: a cross-sectional study from turkey. BMC Public Health 2010;10:413.

33 Liao Q, Cowling BJ, Lam WWT, et al. The influence of socialcognitive factors on personal hygiene practices to protect against influenzas: using modelling to compare avian A/H5N1 and 2009 pandemic $\mathrm{A} / \mathrm{H} 1 \mathrm{~N} 1$ influenzas in Hong Kong. Int $J$ Behav Med 2011;18:93-104.

34 Scott SB, Poulin MJ, Silver RC. A lifespan perspective on terrorism: age differences in trajectories of response to 9/11. Dev Psychol 2013;49:986-98.

35 Shrira A, Palgi Y, Hamama-Raz Y, et al. Previous exposure to the world Trade center terrorist attack and posttraumatic symptoms among older adults following Hurricane sandy. Psychiatry 2014;77:374-85.

36 Charles ST. Strength and vulnerability integration: a model of emotional well-being across adulthood. Psychol Bull 2010;136:1068-91.

37 El-Zoghby SM, Soltan EM, Salama HM. Impact of the COVID-19 pandemic on mental health and social support among adult Egyptians. J Community Health 2020;45:689-95.

38 Fitzpatrick KM, Drawve G, Harris C. Facing new fears during the COVID-19 pandemic: the state of America's mental health. J Anxiety Disord 2020;75:102291

39 Lau JTF, Yang X, Pang E, et al. SARS-related perceptions in Hong Kong. Emerg Infect Dis 2005;11:417-24.

40 Reis BY, Kohane IS, MandI KD. An epidemiological network model for disease outbreak detection. PLoS Med 2007;4:e210.

41 Wei-ping H, Yu-xi M, Li-ying J. Investigation of mental health level of primary and secondary school teachers in Shanxi Province. Theory Pract Educ 2010;10:59-62.

42 Xin-fa Y, Qian Z, Wei-ping H. The cross-temporal analysis of mental health of Chinese teachers:1994 2011. Beijing Norm Univ Soc Sci 2014;3:13-23.

43 Yu-rong L. Analysis on present situation and counter measure for psychological health of middle school teachers. Dalian Edu Univ 2006;3:22-4.

44 Vu C-T, Hoang A-D, Than V-Q, et al. Dataset of Vietnamese teachers' perspectives and perceived support during the COVID-19 pandemic. Data Brief 2020;31:105788.

45 Liu X, Luo W-T, Li Y, et al. Psychological status and behavior changes of the public during the COVID-19 epidemic in China. Infect Dis Poverty 2020;9:58.

46 Leung GMet al. The impact of community psychological responses on outbreak control for severe acute respiratory syndrome in Hong Kong. J Epidemiol Community Health 2003;57:857-63.

47 Rübsamen N, Castell S, Horn J, et al. Ebola risk perception in Germany, 2014. Emerg Infect Dis 2015;21:1012-8. 